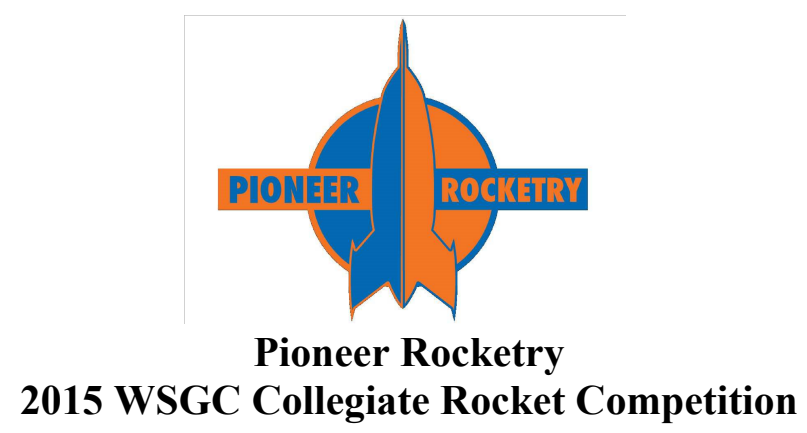

Jake Ellenberger, Adrian Guither, Trent Cybela (et alt.)

Society of Physics Students: University of Wisconsin-Platteville

\begin{abstract}
The objective of the 2015 Wisconsin Space Grant Consortium (WSGC) Collegiate Rocket Competition was to design and build a two stage "Boosted Dart" - style rocket to achieve maximum altitude. The rocket was propelled by a single grain $54 \mathrm{~mm}$ rocket motor (I445 Vmax). Extensive design and modeling was done to optimize the design to achieve maximum altitude. An electronic device designed to measure the rotation of the rocket that would then be correlated to rotation observed with video captured by a camera system. The rocket performed as expected in most aspects, completing most objectives per competition parameters. The flight of the boosted dart however ended in failure, as a delayed ejection of the parachute resulted in compounding failures leading to the loss of the rocket. The camera, having fallen separate from the rocket body, had survived the flight. The video was analyzed and the flights apogee was estimated to be $6000 \mathrm{ft}$. The following report details the design and construction of Pioneer Rocketry's 2015 competition rocket $_{2}$ along with information regarding Pioneer Rocketry's growth as both an educational and professional organization.
\end{abstract}

\title{
Year in Review
}

Pioneer rocketry is now entering its third year of competition, and is now busier than ever before. Due to our success in last year's competition, Pioneer Rocketry has had the privilege presenting before the Dean of Engineering, Math, and Science (EMS) at the University of Wisconsin-Platteville's EMS Industrial Advisory Board Meeting. We were able to not only show Pioneer Rocketry's strength of presence on campus, but also the importance of aerospace and related fields to those who lead the university. We have made our presence known through several appearances on campus promoting Pioneer Rocketry and displaying our competition rockets in display cabinets.

This year Pioneer Rocketry made a greater emphasis on spreading our passion and excitement for both engineering and rocketry, as our team led two outreach events. The first was our instruction of the space exploration merit badge at the Merit Badge Midway hosted here on campus. Through three consecutive weekends our team taught boy scouts about space exploration as well as the design and construction of rockets. The second Pioneer Rocketry led 
outreach event was through Sky's The Limit, an outreach program that introduces young women to careers in STEM fields. We led a group of girls through a rocketry related science experiment that allowed them to think through the scientific process and analyze how the setup for an experiment can affect the results. Pioneer Rocketry has taught about the exciting hobby of High Powered Rocketry and STEM in general to high schools in both Verona and Manawa, Wisconsin.

Beyond expanding Pioneer Rocketry's outreach; this year marks additional changes in how we design, build, and test rockets. This year we are focusing on reducing our reliance on permanufactured parts and creating the ideal rocket for our organization. To achieve this goal we have spent the past year testing the application of 3D printed parts for rocketry. We have explored and validated their use for nosecones and fin construction.

One of the most influential changes since last year would be our ability to launch at Pioneer Farms, the university owned farm. Last spring we were able to obtain a waiver from the FAA to allow us to launch at the farms. Through a great deal of communication with both the university and farm's neighboring Pioneer Farms we were able to set up a launch site here in Platteville. This launch site removed our reliance on the Richard Bong Recreation Area as the only launch site in Wisconsin. We were able to make use of this launch site for the test launch of two boosted dart prototypes. Through these launches we were able to learn invaluable information about the boosted dart concept and the challenges this year's competition brings. In the future the accessibility of the farms as a launch site will allow the rapid testing of rocketry design and construction concepts.

Jake Ellenberger

President, Pioneer Rocketry

\section{Rocket Design}

General Design: The competition parameters for this year called for the development of an unpowered kinetic dart (also referred to as boosted dart), lifted by a separable booster stage. The objective will be to reach the highest altitude possible with the dart, which has no capability of producing thrust. The two stage configuration inspired the name "Thunder \& Lightning" (actual designation PR-3) for the competition rocket - Thunder being the booster, and Lighting being the dart. A graphical cross section of PR-3 is shown in Figure 1. The dart carries a suite of electronics gathering data on both its orientation and altitude. Video is captured from the dart as well from an aft-mounted camera. The following section will break down the main design features of both the booster and dart sections of the rocket.

\section{Dart}

\section{Nosecone}

The nosecone selected for the dart is a PLA 3D printed Nosecone. The shape is a 4.25 in LV Haack and was selected to maximize volume while reducing drag. This volume was 
needed as the nosecone features a compartment to hold a 9 volt battery as well as a $3 / 8$ in bolt counterweight. This nosecone's fineness ratio of 4.65 (length/diameter) was selected after extensive CFD Simulation in the program Star $\mathrm{CCM}+$ to find the optimal ratio between length and diameter. It was determined that increasing the nosecone length will cause the viscous forces of the air to start increasing due to increased surface area. If the nosecone length decreased then the pressure forces will increase due to the increased bluntness of the nosecone.

\section{Airframe}

The body tube selected for the dart is 1.5 in carbon fiber tube. Carbon fiber was selected for two main reasons. The first is the increased strength and reduced weight of the material. The second reason is the resistance to water. Given the wet conditions at the Richard Bong Recreation Area launch site, moisture resistance is an important factor. To minimize the drag on the dart the length of the body tube was minimized. The final length of 18 in was selected as a middle ground between internal volume, for things such as avionics and parachutes, and length reduction for things such as drag.

\section{Weights}

The Dart has the capacity for housing up to $500 \mathrm{~g}$ of counter weight. This modularity will allow the proper selection of weight to maximize altitude. To determine the difference between not enough momentum to overcome drag and too much mass a Simulink model was created. This model takes into account the booster mass and drag as well as the darts mass and drag.

The Simulink model indicates we should have a mass around 765g. An optimization was also run in open rocket to find an optimal mass of $753 \mathrm{~g}$.

\section{Avionics Bay}

The avionics bay consists of a sled between two bulkheads. Two 6-32 threaded rods span the length of the AV bay and tie the nosecone, counterweights, AV sled, and parachute mounting point together. The rods will carry the load of parachute ejection and descent. Refer to the section on electronics titled "Avionics Bay" for further information on the data logging, video, recovery, and deployment systems.

\section{Recovery}

The dart will fly on a 24 in hemispherical parachute made of ripstop nylon features a spill hole. The hemispherical shape and spill hole increase the stability of the parachute during descent. Attaching the parachutes to the rocket is Kevlar shock cord. The Kevlar was selected due to its incredible strength and heat resistance, both of these characteristics are valuable in rocketry. Unlike traditional rockets the parachute is deployed from the bottom of the rocket so there is a reduced chance of breaking fins on impact.

\section{Camera Pod}


Like the nosecone on the dart the tailcone is also 3D printed with PLA plastic.3D printing the tailcone allowed for a simple construction of an otherwise complex geometry which was needed to house the camera. The camera pod is roughly elliptical shape and is shaped around fitting the camera. The camera is sealed inside by a bulkhead attaching to the shock cord. Due to the camera being mounted to the bottom of the rocket and having the camera pod separate, the camera will always be pointed downward and have a view of the ground.

\section{Fins}

The fins on the dart are composed of .06in thick carbon fiber plate. Their shape is trapezoidal, with dimensions that were selected to maximize stability and reduce drag. The fins are swept back at the mid chord 30 degrees to move the center of pressure backwards. The fins also have a higher than normal aspect ratio (span/average chord) with a span of 1.64in. This increased span of the lift generated by the fins. The root chord of the fins is 1.75 in tapering down to a tip chord of $.875 \mathrm{in}$.

\section{Booster}

\section{Transition}

The transition between the dart and booster is the third 3D printed part on this rocket. The Transition serves two purposes on the rocket. The first is to smoothly increase the rocket diameter from the 1.5 in tube of the dart to the 3 in tube of the booster. The second purpose of the transition is to hold the base of the dart during the boost portion of flight. The entire tailcone of the dart as well as 0.25 in of body tube are contained in the transition. Inside the transition there are two plates of wood with the exact profile of the tailcone cut into them allowing for secure retention against rotation and lateral movements but no restriction axially.

\section{Airframe}

Like the dart, the booster tube is also carbon fiber and is 3 in in diameter. To maximize momentum imparted to the dart the booster needs to be as light as possible. To achieve this, the booster was made to be as short as possible. The final length of 14 in was determined to produce an ideal combination between stability and weight.

\section{Recovery}

Due to the similar masses the booster also flies on a 24 in hemispherical parachute. This parachute size and design was determined using the same methods discussed previously with the dart. The shock cord is also Kevlar.

\section{Fins}

For the booster the fins are also made from .06 in carbon fiber. For both aesthetic and aerodynamic purposes they are the same shape as the dart fins but scaled to be much bigger. The root chord is 4.125 in tapering to a tip chord of 2.063 in with a span of 3.867 in. 


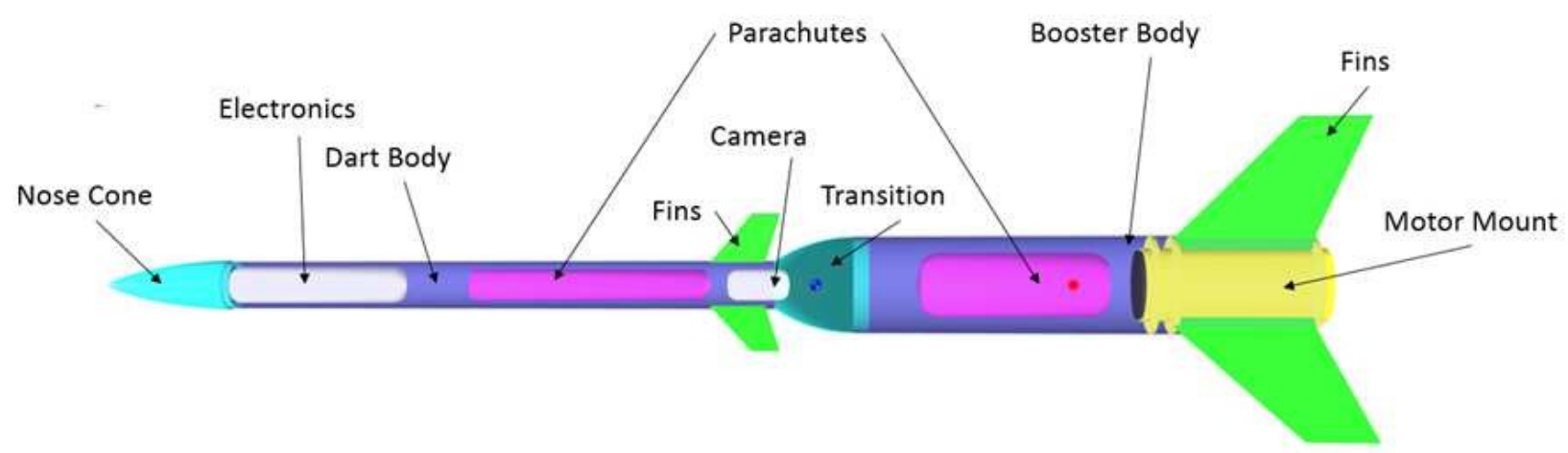

Figure 1: Cross section diagram of PR-3 "Thunder and Lightning"

\section{Stability Analysis}

Based on the open rocket model the stability margin for the combined booster and dart with an unburnt motor is 2.5. At the moment before ideal separation, which occurs at motor burnout, the combined rocket's stability margin will grow to 3.2. The center of gravity will move forward 2.2 in to 21.6 in from the tip of the rocket. As a combined entity the rocket is incredibly stable. After Separation the dart has a stability margin of 3.4. The separated booster has a stability margin of 0.5 . While normally a rocket with a stability margin of 0.5 would raise concerns the fact that the rocket is already moving and stable at the point of separation mitigates these concerns. These claims can be supported through analysis of test flight video taken from the previous prototype dart. In that video you can see the booster trailing behind the dart perfectly stable.

\section{Propulsion System Specifications}

In accordance to the competition parameters, Thunder and Lightning will be flown on a CTI I445-Vmax. This motor provides a more than adequate thrust to weight ratio of 28.8:1. The Vmax propellant is a good propellant choice for a boosted dart style of rocket because the burn time is very short, allowing most of the energy to be transferred to the dart. Flying on this motor, Thunder and Lightning will have a more than adequate velocity of 66 miles per hour upon leaving a six foot rail, ensuring a stable flight.

\section{Anticipated Performance}

To anticipate the performance of the competition rocket, two main tools were used in its both design and simulation. The first of these tools is OpenRocket which throughout the past two years has been extensively used to simulate the team's rocket flights and accuracy its continuity has been validated. OpenRocket serves as Pioneer Rocketry's primary design tool.

The second simulation tool used is a custom made model in Simulink. Simulink is a MathWorks developed graphical programming language tool used for modeling and simulating dynamic systems. The custom model is a simplified 1 dimensional simulation that was created to explore the relationship between rocket characteristics such as dart mass, dart 
drag coefficient, booster mass, and booster drag coefficient on flight performance like apogee, max velocity, and peak acceleration. This tool's purpose in design was to find the optimal mass for the dart to maximize apogee.

For the estimation of apogee an OpenRocket simulation was run under the assumption that separation occurs at motor burnout. This simulation predicts that the rocket has an apogee of $5,140 \mathrm{ft}$. OpenRocket simulations under predicted a previous boosted dart test flight by around $500 \mathrm{ft}$. It is believed that due to the unique nature of the boosted dart in terms of modeling the drag on a tailcone and sensitivity to separation timing led to the inaccurate simulation results. If OpenRocket is overestimating the drag then the predicted apogee of the dart should be higher, somewhere around $5,500 \mathrm{ft}$.

This same OpenRocket simulation was used to estimate the altitude of dart separation. This simulation predicts a separation at an altitude of $500 \mathrm{ft}$. In test flight there was unfortunately had excessive friction between the stages which delayed the separation until several seconds after motor burnout, there was no data that could be compared to predicted altitude.

The Peak Acceleration estimated by the simulation is $28.26 \mathrm{G}$ 's. To compare that to the test flight rocket which had a predicted acceleration of $22.8 \mathrm{G}$ 's and the two raven altimeters measured 24.8G's from the dart and 29.3G's from the booster. While it is not completely understood $5 \mathrm{G}$ difference between two accelerometers on the same rocket it shows that OpenRocket somewhat underestimates the acceleration. Since the results of the simulation are very reliant on the mass of the model being accurate it is predicted that OpenRocket is reliable with its estimation of $28.26 \mathrm{G}$ 's.

\section{Payload System}

This year's competition requirements were to measure and record the pitch, roll, and yaw, of the dart, namely the rotation around the dart's three major axes, during the duration of the dart's flight. Additionally, downward facing video captured from the dart during the airborne period following the launch. To achieve the latter goal, a striped down action camera which mounts inside the secondary electronics bay located in the tail cone of the dart was selected. This configuration allows us to get downward facing video without adding obstructions to airflow to the dart that would increase the air resistance. It also allows the camera to passively reorient to continue taking downward facing video after deployment of the parachute.

The primary challenge was to develop a system that records the rotation of the boosted dart during its flight for later comparison with our flight video. To do this a sensor kit around an Arduino Micro was built. This system utilizes a 9 Degree of Freedom sensor capable of recording the angular acceleration of the rocket as well as the magnetic field found at the rocket. The angular acceleration can be integrated to find the rocket's rotation. The earth's magnetic field will have a very nearly constant strength and direction, and this will be utilized to determine the rockets orientation. 


\section{Construction}

This year's competition posed many unique challenges to construction, due to the unique boosted dart design. This is the first $54 \mathrm{~mm}$ motor, the smallest diameter, and the shortest rocket that Pioneer Rocketry has ever built.

A new construction technique, namely surface mounted fins, was used because of the unique design of this year's competition rocket and the inability to extend the fins through the darts body tube. This type of fin only appears on the dart; the booster section has traditional through the wall fins with precision milled fin slots. Laser cut fin guides were also used to ensure proper alignment of the fins.

Also, new from previous years is the addition of multiple new materials, including carbon fiber airframe, carbon fiber fins, and various 3D printed components. Because of the added strength of the carbon fiber airframe and fins, we chose not to fiberglass over the fins.

When dealing with potentially harmful materials, all proper safety measures were observed. Material safety data sheets were available for all volatile materials and proper safety equipment such as glasses and respirators were utilized.

The laser cutter was extensively used during the construction of the rocket. Components made on the laser cutter include bulkheads, centering rings, electronics sleds, and a cradle to hold the dart in place during boost.

\section{Empirical Testing}

In order to prepare for the new concepts introduced by this year's competition, the booster section of a previously built Super DX3 that was previously used in a level 1 certification. The resulting rocket was dubbed the Super DartX3. Although the Super DartX3 was not a success due to several staging failures, a great deal was learned about the boosted dart concept and the challenges it brings. The Super DartX3 was our first rocket to utilize surface mounted fins, as well as 3D printed fins.

Building on what was learned from the Super DartX3, a prototype competition rocket was constructed, named "Dazed and Confused" for its ultra-visible paint scheme. In building this rocket, the goal was to be as close as possible to the final competition rocket. Dazed and Confused fixed the staging problems that had plagued the Super DartX3's test flight but unfortunately non fire resistant shock cord was used, resulting in a ballistic trajectory ending in a high velocity impact. In-flight video showing the stage separation can be seen in Figure 2. In the future, Kevlar shock cord will be used because it is sufficiently fire retardant. 


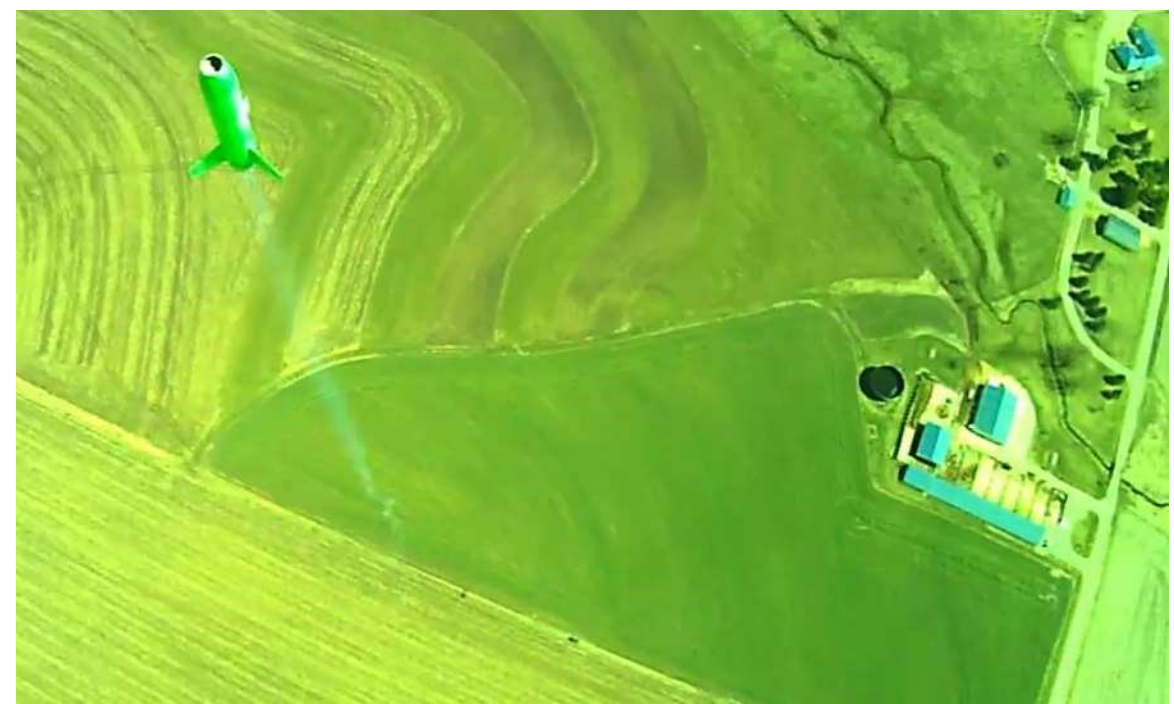

Figure 2: Image taken from the Dazed and Confused, dart section video camera during ascent-

Conclusion: Pioneer Rocketry has been blessed with a lot of success this past year. Moving forward, we have worked with the University of Wisconsin-Platteville to obtain a launch location near campus. We have worked hard to fully utilize these opportunities, and we are grateful for all the guidance, assistance, and funding provided by the Wisconsin Space Grant Consortium and Tripoli Rocketry.

Our member base is not small, and for this reason Pioneer Rocketry is modeled differently than most contenders in this competition. Our intent is to become more than just an isolated group of rocketeers, but rather to become an integral part of our University's selection of student organizations. It is our hope that over the coming years we will expand our membership, build more rockets, conduct more launches, receive more High Powered Rocketry certifications, and lend credit to the use of aerospace applications as part of an undergraduate college curriculum. 